\title{
UM OLHAR SOBRE A EDUCAÇÃO ESCOLARIZADA DE SURDOS À LUZ DA COMPETÊNCIA EM INFORMAÇÃO
}

\author{
Maria Margarete da Silva* \\ Gustavo Henrique de Araújo Freire*
}

Palavras-chave: Atendimento Educacional Especializado. Inclusão escolar de surdos. Competência em informação. Ações de informação. Abordagem bilíngue.

O presente artigo aborda a educação escolarizada de surdos à luz da competência em informação, tomando como referencia - Atendimento Educacional Especializado (AEE) para pessoas surdas. Apresenta no marco teórico uma abordagem dos aspectos legais e pedagógicos do $\mathrm{AEE}$, aqui tratado como lócus do Atendimento Educacional Especializado. Aborda, ainda, aspectos teóricos da competência em informação e de ações de informação. Tem como objetivo analisar o AEE na Escola Professora Adelina Almeida em Petrolina PE, na perspectiva do desenvolvimento de Competência em informação para inclusão social de alunos surdos. A investigação do objeto de estudo teve como método a pesquisa-ação, de natureza aplicada, numa abordagem qualitativa, cujos resultados evidenciam ações concretas voltadas para o desenvolvimento de competência em informação e propiciadoras de novas estratégias didáticas na condução do aprender sempre e em todas as dimensões da vida.

\footnotetext{
* Mestre em Gestão em Organizações Aprendentes pela Universidade Federal da Paraíba, Brasil. Especialista em Metodologia do Ensino Superior pela Universidade Federal de Pernambuco, Brasil. Gestora da Escola Professora Adelina Almeida em Petrolina, Pernambuco, Brasil.

E-mail: maria.margsilvaufpb@gmail.com.

** Doutor em Ciência da Informação pela Universidade Federal do Rio de Janeiro, Brasil. Docente permanente doPrograma de Pós-Graduação em Ciência da Informação da Universidade Federal da Paraíba, Brasil.

E-mail: ghafreire@gmail.com.
}

\section{INTRODUÇÃO}<smiles>O</smiles>
presente trabalho apresenta uma rede conceitual acerca da competência em informação e situa essa temática dentro das ações de informação realizadas na educação escolarizada de surdos, visando à aquisição de um embasamento teórico para verificar, no campo empírico desta pesquisa, as competências informacionais desenvolvidas por alunos surdos, inclusos no ensino regular, a partir de um olhar para o Atendimento Educacional Especializado (AEE), aqui apresentado como um dos objetivos da Política Nacional de Educação Especial na Perspectiva Inclusiva.

Como lócus privilegiado para a organização dos processos de ensino e aprendizagem de surdos, apresentamos a Escola
Professora Adelina Almeida, em Petrolina, onde funciona a sala de recursos multifuncionais ou sala de AEE, cujas atividades desenvolvidas nesse espaço têm como fundamento legal e pedagógico a abordagem bilíngue que, mediada pelas tecnologias, assume um caráter inovador no processo de criação, socialização e utilização da informação de forma competente.

Para tratar das questões teóricas e práticas relativas à competência, cruzamos diversas teias conceituais construídas por Perrenoud (2013), Sacristan (2007), Levy (1999), Ropé; Tanguy (1997), Bourdieu (1982), Le Boterf (1994), Jonnaert (2010) Nascimento; Freire; Dias (2012), Castells (2003) e Silva Neto; Freire, (2014). Essa tessitura teórica trouxe sustentação à busca de evidências da competência em informação na práxis dos sujeitos organizacionais, em seu movimento cotidiano sem, contudo, desconsiderar 
as especificidades dos percursos por ela desenhados, os eixos comuns da discussão e as fragilidades relacionadas a sua "definição", "evidência" e "missão", como anuncia Perrenoud (2013).

Buscamos, ainda, em Gonzalez de Gomez (2003), Freire (2013, 2014), Collins e Kush (1999), elementos para compreender a dinâmica das ações de informação desenvolvidas no lócus do atendimento educacional especializado, à luz da competência em informação.

Visando identificar os elementos teóricos materializados no terreno fértil do campo empírico da pesquisa, seguimos um caminho metodológico iluminado pela pesquisa-ação, de natureza aplicada, que numa abordagem qualitativa, possibilitou o alcance do objetivo da nossa pesquisa, qual seja ,analisar a educação escolarizada de surdos, a partir do atendimento educacional especializado (AEE) na Escola Professora Adelina Almeida em Petrolina-PE, sob o viés da competência em informação para inclusão social de alunos surdos.

A definição desse objetivo foi decisiva para a construção do caminho metodológico para o desvelamento da realidade acerca da competência em informação, no cerne do Atendimento Educacional Especializado (AEE), na escola em que foi realizada a pesquisa.

\section{ATENDIMENTO EDUCACIONAL ESPECIALIZADO NA EDUCAÇÃO ESCOLARIZADA DE SURDOS}

O Atendimento Educacional Especializado (AEE) para surdos, orientado pela Política Nacional de Educação Especial na Perspectiva da Educação Inclusiva de 2008, tem como local de oferta na escola, a sala de recursos multifuncionais, que consiste num espaço físico contendo mobiliários, materiais didáticos, recursos pedagógicos de acessibilidade e professores capacitados para ministrar aulas utilizando a Língua Brasileira de Sinais (LIBRAS), como meio de comunicação e interlocução entre o professor, o conteúdo e o aluno surdo.

Considerando a pessoa surda como “aquela que, por ter perda auditiva, compreende e interage com o mundo por meio de experiências visuais, manifestando sua cultura principalmente pelo uso da Língua Brasileira de Sinais - Libras" a organização pedagógica da sala de AEE supõe a utilização de muitas imagens ou outros subsídios que possam contribuir com a aprendizagem dos conteúdos estudados em sala de aula. (BRASIL, 2005, p. 1),

Contudo, as atividades a serem realizadas na sala de AEE devem ter como fundamento legal e pedagógico a abordagem bilíngue, garantida pelo Decreto 5.626, de 22 de dezembro de 2005, que visa preparar alunos surdos para utilizar tanto a Língua Brasileira de Sinais (LIBRAS), aqui tratada como primeira língua (L1), quanto a segunda língua (L2), qual seja a língua dos ouvintes da comunidade onde os surdos estão inseridos.

Todavia, estudos voltados para a área da surdez têm demonstrado que a abordagem baseada no bilinguismo tem apresentado eficácia "em virtude de respeitar a língua natural e construir um ambiente propício para a aprendizagem escolar" (BRASIL, 2010, p. 7). Com efeito, "o ambiente educacional bilíngue é importante e indispensável, já que respeita a estrutura da Libras e da Língua Portuguesa", e por entender que a negação do bilinguismo se constitui numa redução da autonomia dos surdos perante o mundo e, por conseguinte, na minimização das possibilidades de construção de competência em informação para uma inclusão efetiva na vida social e no trabalho. (DAMÁZIO, 2007, p. 37).

Dito de outra forma, a ausência do estudo da Língua Portuguesa para alunos surdos, além de se constituir num descumprimento da legislação em vigor, a nosso ver, limita as possibilidades dos alunos surdos realizarem leitura e compreensão dos conhecimentos acumulados ao longo dos tempos e reduz as possibilidades apropriação das várias literaturas disponíveis, majoritariamente, em Língua Portuguesa no caso do Brasil.

A rigor, para que a pessoa surda tenha suas especificidades atendidas, conforme o Manual de Orientação: Programa de Implantação da Sala de Recursos Multifuncionais (BRASIL, 2010), faz-se necessário que os profissionais do AEE construam um plano de atendimento que contemple a diagnose das habilidades e necessidades específicas dos alunos surdos, cronograma de atendimento, recursos pedagógicos necessários, relação de professores, intérpretes e instrutores que atendem na sala de 
AEE, os obstáculos que interferem no processo de aprendizagem e de inclusão e o modo organizacional de avaliação da aprendizagem, para verificar pontualmente a contribuição do Atendimento Educacional Especializado para o aluno surdo matriculado na escola regular (DAMÁZIO, 2007).

A partir desse plano, que visa potencializar o planejamento, a execução, o monitoramento e a avaliação das ações a serem desenvolvidas na sala de AEE, e em conformidade com o decreto 5.626/ 2005, o aluno surdo tem direito a três momentos didáticos na escola, tais como: o atendimento educacional especializado em Libras, aqui referendado como o atendimento de complementação e suplementação da aprendizagem a ser realizado, preferencialmente, na sala de AEE; o Atendimento Educacional Especializado de Libras oferecido àqueles que não têm, ainda, o domínio da Libras; e o Atendimento Educacional Especializado da Língua Portuguesa, no caso do Brasil.

Com efeito, as tecnologias digitais, em especial, a internet, podem ser integradas às ações do AEE de forma inovadora em atividades de pesquisa e de comunicação que integrem professores e alunos surdos em atividades voltadas para o envolvimento entre grupos dentro e fora da escola, seja através de redes sociais ou ainda para publicação de atividades, eventos em paginas de web, vídeos, blog. Ou, ainda, na complementação das aprendizagens e na criação de novas possibilidades de interação, de construção de conhecimento e por que não dizer, na construção de competência em informação, já que

\footnotetext{
[...] ○ aprendizado baseado na Internet não é apenas uma questão de competência tecnológica: um novo tipo de educação exigido tanto para se trabalhar com a internet quando para se desenvolver a capacidade de aprendizado numa economia e numa sociedade baseada nela. A questão crítica é mudar do aprendizado para o aprendizado-de aprender, uma vez que a maior parte da informação está online e o que é realmente necessário é a habilidade para decidir o que procurar, como obter isso, como processá-lo e como usá-lo para a tarefa especifica que provocou a busca da informação (CASTELLS, 2003, p. 20I).
}

Maximizando esse entendimento Moran (2013), atesta que os professores devem incentivar a busca e a pesquisa na internet, aumentando a complexidade das atividades à medida que eles demonstrarem avanços a partir dos níveis mais simples. Importante, ainda, é o professor incentivar seus alunos a saberem fazer perguntas, priorizar questionamentos importantes, construir critérios de escolhas de sites e páginas a serem consultadas, a fazer comparações entre textos diversos para perceber ideias semelhantes e divergentes a partir de visões diferentes.

Importante considerar, ainda, que as ações a serem desenvolvidas na educação escolarizada em todo processo educativo que envolve os surdos, à luz da competência em informação, deve estar pautada na Proposta Pedagógica da Escola, tendo como lócus de desenvolvimento a sala de recursos multifuncionais, de onde se pode visualizar o tamanho do impacto que as ações ali desenvolvidas provocarão e se provocarão na educação, numa lógica de construção de competências em informação que proporcionem uma real igualdade de oportunidades e enriquecimento para todos.

\section{A REDE CONCEITUAL DA COMPETÊNCIA EM INFORMAÇÃO}

Nos últimos anos, o termo competência tem entrado na pauta das discussões empresariais e acadêmicas sob vários enfoques e à luz de várias concepções teóricas, inclusive com base no senso comum. Em contrapartida, há uma discussão histórica da necessidade de se construir competências para o enfrentamento da vida desde a escola.

Contudo ressaltamos que construir competência, sobretudo competência em informação, carece da inclusão desse campo conceitual nas discussões atuais, na realidade vivida e no contexto onde se insere, visando o entendimento de como desenvolvê-la na práxis dos sujeitos organizacionais em seu movimento cotidiano, o que sugere uma tecitura dos fios dessa trama visando à construção de pistas para o seu desvelamento.

Destarte, o entendimento do campo semântico da competência traz certas fragilidades como aponta por Perrenoud (2013). A primeira delas diz respeito à definição, à forma vaga e 
incerta como o termo competência se apresenta a cada ator que a procura, tornando difícil saber de que competência se está falando ou se quer desenvolver, já que cada ator define a sua maneira, a partir de um referencial próprio ou de uma situação apresentada. A segunda, refere-se à fragilidade empírica no que diz respeito à confirmação da evidência. E, a terceira fragilidade, diz respeito à missão da escola.

Ao apontar a missão da escola como uma fragilidade Perrenoud (2013) questiona se é missão da escola preparar para a continuidade dos estudos ou desenvolver competências visando à preparação para a vida. Ou, ainda, como alerta Sacristan (2007) se essa missão se presta ao desenvolvimento de ações de "concreta utilidade produtiva" que possibilite aos sujeitos a preparação para uma vida real (SACRISTAN, 2007, p. 55). Enriquecendo essa discussão, Levy (1999, p. 157), afirma que "os percursos e perfis de competências são todos singulares", exigindo, conforme (ROPÉ; TANGUY, 1997) que se leve em consideração as situações concretas, o contexto e os indivíduos, pois não é possível dar uma definição a essas noções de maneira separada dos sujeitos e das tarefas nas quais a competência se materializa.

Buscando o entendimento de como se percebe e se constrói essa competência é preciso considerar que, para ser competente em informação, de acordo com a American Library Association (1989), citada por Amadeo (2012, p.15) "uma pessoa deve ser capaz de reconhecer quando a informação é necessária e ter a habilidade para localizar, avaliar e usar efetivamente essa informação". Nesse entendimento, Bourdieu (1982), citado por Ropé e Tanguy (1997), sugere prudência ao analisar o espaço que as palavras ocupam nos discursos e na construção dos desígnios sociais, evitando pronunciamentos do tipo: aquele aluno é muito competente ou aquele aluno não tem competência, já que o conceito de competência se insere em diferentes campos conceituais e pode fazer referência a diferentes problemáticas dependendo do contexto social, econômico, educacional e em função da atividade a ser desenvolvida por um sujeito que se diz competente.

Diante do exposto, torna- se "impossível propor uma visão única de competência", o que exige considerar a singularidades dos perfis e a atuação dos sujeitos nas suas atividades cotidianas (BOURDIEU apud PERRENOUD, 2013, p. 45). Enriquecendo essa trilha teórica, Le Boterf (1994), citado por Perrenoud (2013, p. 45) afirma que

[...] a competência não é um estado, e sim um processo, um saber agir. $O$ operador competente é aquele que é capaz de mobilizar e colocar em prática, de modo eficaz, as diferentes funções de um sistema no qual intervêm recursos tão diversos quanto às operações de raciocínio, os conhecimentos, as atividades da memória, as avaliações, as capacidades relacionais ou os esquemas comportamentais.

Ampliando Le Boterf, Jonnaert (2010) explica que competência é percebida em processo, na ação e, portanto, não é algo que se pode prever. Contudo, ela está relacionada a uma situação ou grupo de situações e ao campo da experiência, e tem como elemento de maior destaque, a presença de uma pessoa na coordenação e atuação.

Diante disso, torna-se um equívoco olhar a competência por um único viés, já que ela potencializa a resolução de problemas a partir de diferentes campos conceituais e faz referência a diferentes problemas e situações, no entanto para efeito da nossa pesquisa, é importante destacar as competências em informação propostas por Perrenoud (2000, p. 12), quais sejam:

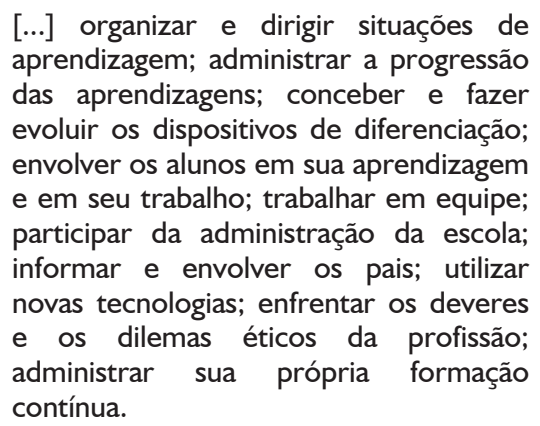

Contudo, numa leitura de Perrenoud (2013, p. 45), há um consenso na definição de competência como sendo "o poder de agir com eficácia em uma situação, mobilizando e combinando, em tempo real e de modo pertinente, os recursos intelectuais e emocionais", sem perder de vista as categorias apresentadas por Sacristan (2007), quais sejam o uso do 
conhecimento, da informação e da tecnologia de forma interativa, sem as quais teremos consequências sociais graves. Nesse viés, Castells (2003, p. 211) aponta que:

\begin{abstract}
[...] se há um consenso acerca das consequências sociais do maior acesso à informação é que a educação e o aprendizado permanente tornam -se recursos essenciais para o desempenho no trabalho e o desenvolvimento pessoal. Embora aprendizado seja mais amplo que educação, as escolas ainda tem muito a fazer com relação ao processo de aprendizado [...] mas a internet e a tecnologia educacional em geral só são vantajosas quando os professores se mostram preparados.
\end{abstract}

Isso nos faz supor que um dos grandes desafios da escola é desenvolver competências para a construção de uma "sociedade na qual todos os indivíduos ou grupos sociais sejam capazes de criar, utilizar e acessar informação e conhecimento de modo eficiente" e, por conseguinte, uma sociedade que potencialize indivíduos competentes em informação (NASCIMENTO; FREIRE; DIAS, 2012, p. 174). Em contrapartida, a escola carece de ter um olhar para esse novo desenho da sociedade que é a sociedade da informação, aqui tratada como aquela que convive com uma evolução tecnológica sem precedentes, marcada pela atividade acelerada da comunicação em rede, que além de potencializar a criatividade na pesquisa e na investigação, pressupõe um profundo restabelecimento de todas as relações que envolvem o processo de ensinar e aprender.

Esse pressuposto nos põe diante de um dilema que é o de investigar se a escola está considerando essa nova arquitetura da sociedade da informação e se, de forma efetiva, está potencializando nos sujeitos envolvidos a necessária competência em informação, já que diferentemente do pedreiro, que ganha competência na área da construção civil no exército prático, a competência do futuro trabalhador se constrói essencialmente na escola, "antes de ser testada no mercado de trabalho" (STROOBANTS apud ROPÉ; TANGUY, 1997, p. 159).

Esse entendimento nos coloca diante de outro desafio, que é "identificar as formas adequadas de formação de professores para que os mesmos possam fazer uso adequado das tecnologias digitais no ensino", que, a nosso ver, conduzem ao aprendizado contínuo e ao desenvolvimento de competências em informação (SILVA NETO; FREIRE, 2014, p. 47).

Identificar, ainda, quais competências estão sendo trabalhadas na escola e que ações estão sendo desenvolvidas, a fim de possibilitar a preparação para a vida, pois "nada nos diz qual seria o uso que os alunos fariam dos saberes e competências disciplinares fora de sua vida escolar e depois da sua escolaridade numa vida que, evidentemente, não é disciplinar" (AUDIGIER, 2010, apud PERRENOUD, 2013, p. 65).

Nesse sentido a sociedade da informação, sugere através de uma prática interdisciplinar, que a escola vislumbre a construção de ações de informação que potencializem novas formas e fontes de acesso, utilização, análise e avaliação da informação, com vistas ao atendimento das exigências atuais do mundo acadêmico e profissional, que hoje assume novos contornos e exige o desenvolvimento de competência em informação.

\section{AÇÕES DE INFORMAÇÃO}

Levando em consideração que tratar de ação de informação requer um estudo do que seja esse fenômeno e das formas pelas quais se manifesta nas organizações, buscamos um caminho a partir de Gonzalez de Gomez (2003b, p. 34) que define a ação de informação como sendo

[...] um conjunto de estratos heterogêneos e articulados identificados como: a) de informação(semânticopragmática), estrato polimórfico que se define nos inúmeros setores da produção social sob a forma de ações narrativas; b) de meta-informação, estrato regulatório definido nos espaços institucionais do Estado, do campo científico, da educação formal, da legislação e de contratos; c) de infraestrutura de informação, estrato mimeomórfico dos objetos de informação, definido na indústria e nos mercados das tecnologias, das máquinas e dos produtos mediante ações técnico e econômicas, normas técnicas modelos.

Maximizando esse entendimento, apresentamos através da figura a seguir, os estratos, domínios e modalidades das ações de informação, 
Figura 1 - Estratos, domínios e modalidades das ações de informação.

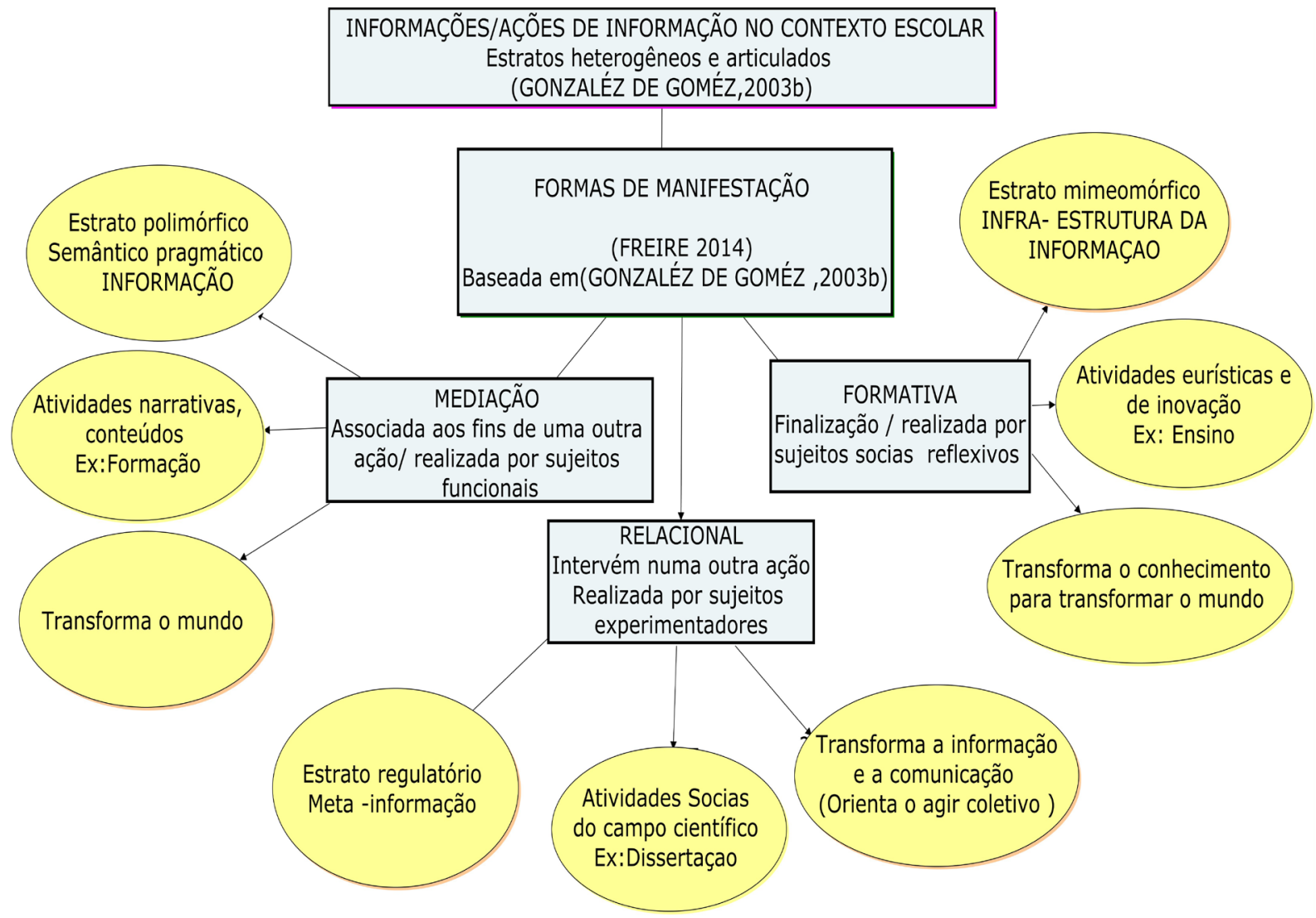

Fonte: Elaborado pelos autores (2016), baseados em Freire (2014).

Contudo, para orienta a percepção das evidências dessas ações, Freire (2013, p. 76), ancorada em Gonzalez de Gomez (2003b), apresenta três modalidades de manifestação da ação de informação, a saber: mediação, formação e relacional que, dependendo do contexto em que ocorrem, podem se revelar de formas variadas.

Reforçando esse entendimento, González de Gómez (2003b, p.36), apoiada nas categorias de Collins e Kush (1999), apresenta as possibilidades de manifestação das informações através da numa outra ação de informação, de modo que - ainda quando de autonomia relativa - dela obtém a direção e fins).

Nesse ínterim, ação de mediação, conforme Gonzalez de Gomez (2003a, p. 77), visa orientar outra ação dos sujeitos, aqui tratados como funcionais, cuja prática é definida no contexto de sua atuação, no interior das várias atividades sociais vislumbrando a transformação do mundo social ou natural. Já a modalidade formativa, produzida por "sujeitos heurísticos" ou "experimentadores", visa transformar o conhecimento para, assim, transformar o mundo, referendada pelas transformações dos "modos culturais de agir e de fazer, nas artes, na política, na ciência, na indústria e no trabalho, iniciando um novo domínio informacional", que assume um caráter de finalização e não de meio (GONZÁLEZ DE GÓMEZ, 2003b, p. 36).

Por sua vez, a modalidade relacional, enquanto meta-informação desenvolvida por 
sujeitos sociais articuladores, diz respeito a informação que procura intervenção em outra ação "para dela obter direção e fins, ampliando seu espaço de realização" e sugerindo uma intervenção nas organizações. Ação que assume materialização nas organizações através de resultados de pesquisas sistematizadas em dissertações, por exemplo, (GONZÁLEZ DE GÓMEZ, 2003b, p. 37).

Ainda, na perspectiva de Gonzalez de Gomez (2003b), para uma melhor conceitualização, sugerimos pensar a ação de informação a partir de uma relação estreita com a "ação social como forma de vida" que, por conseguinte, apresenta singularidades que a faz diferente de outros modos de ação e "formas de vida".

Isso posto, podemos dizer que esse modelo teórico de ações de informação aqui apresentado se encontra materializado nas ações das escolas a partir de aulas expositivas e dialogadas, momentos de formação de professores, palestras envolvendo a comunidade escolar, oficinas, seminários, entre outras ações, numa relação dialética com os seus atores representados pela comunidade escolar (pais, alunos, professores, gestores, coordenadores, analistas educacionais).

Todavia, conforme Freire (2014, p. 138), há que se considerar que na essência dessa abordagem, a arquitetura da "comunicação em rede mediada pela Internet adquire inestimável valor no que concerne ao atendimento de necessidades informacionais dos sujeitos sociais" envolvidos, na formulação de sugestões, na construção de propostas de ações de informação, bem como na potencialização de competência em informação.

\section{COMPETÊNCIA EM INFORMAÇÃO NO LÓCUS DO AEE: A TRILHA METODOLÓGICA E O CAMPO DA PESQUISA}

Para construir a trilha metodológica em busca de evidências da competência em informação na educação escolarizada de surdos buscamos inspiração em Brasileiro (2013), que nos direcionou para um caminho metodológico baseado na pesquisa-ação, de natureza aplicada, numa abordagem qualitativa, visando potencializar os resultados obtidos para a resolução de problemas reais da comunidade campo de pesquisa, nesse caso, a Escola Professora Adelina Almeida (EPAA), localizada na Avenida Monsenhor Ângelo Sampaio, S/N, no Bairro Areia Branca, Petrolina-PE.

Essa instituição iniciou suas atividades em 1969 e, considerando o dedicado trabalho com a "inclusão de alunos com deficiência intelectual em salas de ensino regular", em 1990 foi reconhecida, pela comunidade do Vale do São Francisco, como Escola de Referencia em Educação Especial (ARAUJO, 2015, p. 31). E, embora o Atendimento Educacional Especializado (AEE) estivesse legalmente garantido desde a promulgação da Constituição Federal de 1988, somente em 1992 teve início, na Escola esse o serviço para alunos com deficiência auditiva matriculados no ensino regular, mesmo de forma itinerante.

Todavia, o AEE, na EPAA, somente se efetivou na sala de recursos multifuncionais a partir de 2008, quando a Escola recebeu do Ministério de Educação e Cultura (MEC) materiais como: computadores acessíveis, data show, computadores convencionais, televisão, impressora Braille e vários materiais de apoio didático (livros e jogos diversos em Braille e em Libras).

Hoje, na condição de Escola Polo de Ensino Médio, continua com expressivas ações voltadas para a inclusão de pessoas com deficiência onde se constata, consolidado na proposta pedagógica da Escola, um plano de formação continuada, coordenado e desenvolvido pelos próprios professores, juntamente com a coordenação pedagógica e a equipe gestora. Esse plano atende as necessidades da comunidade interna e externa através de formação, tanto no tocante aos referenciais teóricos que orientam o desenvolvimento de competências informacionais para surdos, como na construção da proficiência em Libras.

Durante a pesquisa foi identificado na sala de atendimento educacional especializado, um painel com a relação dos alunos matriculados no AEE e com seus respectivos horários de atendimento, especificando, também, o professor responsável pelo atendimento e um cronograma de formação em Libras para pais, professores e alunos ouvintes.

Vale ressaltar que o processo de inclusão de alunos especiais em classes regulares somente 
se efetivou com mais intensidade a partir de 2008, com o advento da Política Nacional de Educação Especial na Perspectiva Inclusiva. E, embora houvesse resistência por parte dos pais e responsáveis pela inclusão dos alunos especiais em classes regulares, o processo de inclusão na EPAA foi se intensificando em cumprimento a essa Política e, por conseguinte, AEE foi sendo consolidado na Proposta Pedagógica da Escola e nas ações concretas vivenciadas por professores e alunos surdos.

E, embora todas as ações direcionadas para o AEE envolvam os funcionários da EPAA, de um modo geral, o trabalho para o desenvolvimento das competências informacionais dos alunos surdos está diretamente relacionado aos docentes das salas regulares nas quais os surdos estão inclusos; aos intérpretes que atuam diariamente nas salas de aulas regulares traduzindo para Libras os conteúdos apresentados em Língua Portuguesa; e aos instrutores surdos que desenvolvem o ensino de Libras, promovendo o enriquecimento do vocabulário científico através do trabalho com sinais desconhecidos pelos alunos surdos.

Apesar das evidências de que todos os funcionários da escola pesquisada se relacionam e se comunicam com os surdos, mesmo que de forma limitada por não dominarem a Libras, dos 95 funcionários da escola, são 54 que têm envolvimento direto nas atividades pedagógicas com surdos, conforme mostra o gráfico a seguir.

Gráfico 1 - Profissionais que atendem diretamente aos surdos.

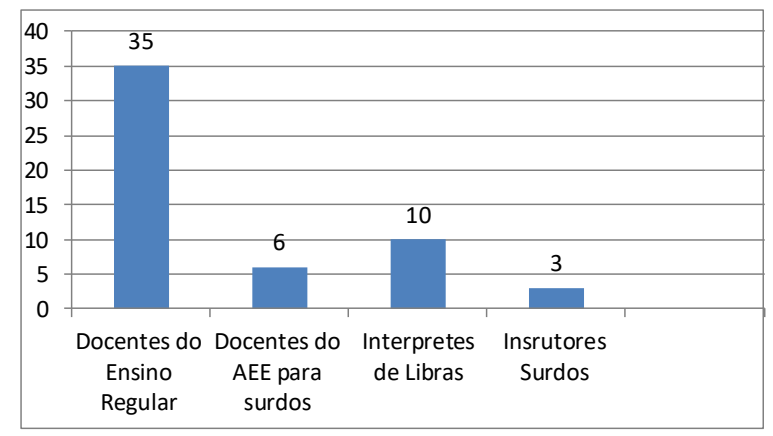

Fonte: Dados da pesquisa.

Vale ressaltar que dos 35 professores do ensino regular, apenas quatro participam de cursos de Libras e desenvolvem, de forma principiante, diálogos informais com os surdos. Já nas atividades diárias, em sala de aula, continuam subsidiados por um intérprete de Libras que traduz, simultaneamente, o conteúdo oficial trabalhado em sala de aula.

Com relação ao corpo discente, no cenário atual, a Escola Professora Adelina Almeida (EPAA) funciona em três turnos e conta com um quantitativo de 938 alunos matriculados. Desses, 23 (\%) são alunos deficientes intelectuais matriculados no Ensino Fundamental Inicial Especial (EFAIESP); 446 encontram-se matriculados no Ensino Fundamental Final (EFAF9); 438 no Ensino Médio (ENME); e 31 no Programa Travessia Médio.

Conforme distribuídos no gráfico a seguir, do total de alunos, em atendimento ao aspecto transversal da educação especial em todos os níveis e modalidades de ensino, cinquenta e um alunos são surdos inclusos no Ensino Regular e no Programa Travessia Médio.

Gráfico 2 - Matrícula geral da EPAA x alunos surdos

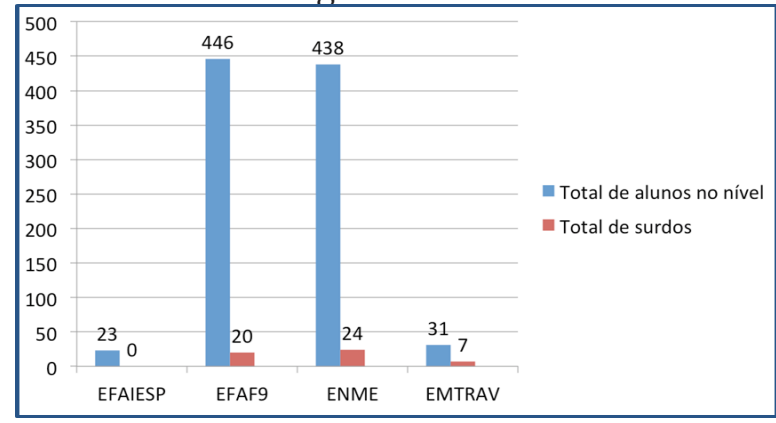

Fonte: Portal do SIEPE (2015).

Como se pode observar, a turma do EFAIESP é constituída de 23 alunos que, conforme dados da pesquisa, apresentam acentuada deficiência intelectual. Em função disso, segundo os professores de $\mathrm{AEE}$, não seria pertinente matricular surdos nessa turma, pois assim poderia inviabilizar a educação bilíngue.

No entendimento dos professores da instituição estudada, a educação de surdos no Ensino Fundamental Inicial - em função do estudo da Libras como primeira língua deve se dar em classe especial, e não de forma inclusa, uma vez que numa classe regular ou numa sala especial constituída de alunos com deficiência intelectual, auditiva, visual, por exemplo, ou de alunos sem deficiência, a 
língua materna empregada seria o português e, consequentemente, todo ensino estaria pautado nessa língua.

Ademais, na compreensão dos professores de AEE, essa educação bilíngue nos primeiros anos do ensino fundamental, deve ocorrer numa sala somente de surdos, já que eles ainda não têm o domínio da língua materna (Libras) e necessitam de um tempo pedagógico maior com seus pares para se apropriarem da linguagem de sinais, que na concepção dos professores, esse posicionamento não contraria os princípios inclusivos da Política Nacional de Educação Especial na Perspectiva Inclusiva, pelo contrário fortalece-a, uma vez que prepara os alunos surdos do EFAIESP no aprendizado de Libras para uma inclusão mais fortalecida no EFAF9.

Entretanto, como detalhado no quadro 1, mesmo constando nos documentos legais e pedagógicos, a educação bilíngue ainda não está garantida na escola pesquisada, pois embora a legislação assegure direito a atendimentos de Libras, em Libras e de Língua Portuguesa como segunda língua, apenas dois desses momentos didático-pedagógicos são oferecidos aos alunos surdos matriculados na Escola.

Quadro 1 - Atendimento educacional especializado para alunos surdos na EPAA.

\begin{tabular}{cl}
\hline & a) Em Libras: realizado por \\
professor ouvinte e proficiente \\
eEE para & em Libras para traduzir/explicar \\
surdos na & os conteúdos curriculares oficiais \\
EPAA & usandoa Linguagem Brasileira de \\
& Sinais (Libras), potencializando, \\
ainda, reforçar aprendizagens de \\
conteúdos já ensinados na sala \\
de aula regular. \\
b) De Libras: Ensino de Libras \\
realizado por instrutor surdo \\
e proficiente em Libras. \\
Esse trabalho favorece o \\
conhecimento de termos \\
científicos e fornece a base \\
conceitual dessa língua.
\end{tabular}

Esse Atendimento Educacional Especializado em Libras, que ocorre na sala de AEE, visa reforçar ideias essenciais trabalhadas no cotidiano da sala regular e se presta a oferecer uma revisão de conteúdos curriculares estudados para que o aluno surdo possa tirar eventuais dúvidas ainda não sanadas, momento em que os professores do AEE se utilizam de diversos recursos visuais, dominó, quebra-cabeça, jogo da memória e, em escala bem menor, os jogos on-line. E, e quando o conceito ou o conteúdo é muito abstrato, recorrem a outros recursos, como o teatro e a dramatização.

As tarefas propostas para casa são realizadas, na sua maioria, na sala de AEE onde os alunos, juntamente com o professor, proficiente em Libras, realizam pesquisas utilizando livros e, com mais frequência, a ferramenta de busca Google. Também, juntamente com os professores de AEE, os alunos organizam os materiais a serem apresentados em sala a partir da utilização de programas de edição de texto, como o Word, PowerPoint e, com bem menos frequência, o Excel.

Entre os artefatos de informação utilizados pela comunidade da Escola, evidencia-se o uso expressivo do data show e uma predominância do uso do celular para pesquisa e disseminação da informação e troca de mensagens para informar eventuais mudanças no cronograma do plano de ação e para informes de modo geral. Essas são ferramentas importantes, pois, considerando que os surdos são muito visuais, esses artefatos facilitam a aprendizagem, a comunicação, a busca e a disseminação da informação.

No tocante a Língua Portuguesa (L2), embora, ainda, não tenha encontrado espaço de desenvolvimento na Escola Professora Adelina Almeida (EPAA) na sua totalidade, a comunidade escolar entende que ela representa a possibilidade de desenvolvimento de uma competência, ainda não adquira pela maioria dos surdos, que é compreender essa língua nos níveis morfológico, sintático e semântico-pragmático e, assim, apropriar-se de um conhecimento já adquirido naturalmente pelos ouvintes, que é o reconhecimento da estrutura da Língua Portuguesa.

E, mesmo sabendo da existência de livros escritos na Linguagem Brasileira de Sinais, constatamos que a grande maioria dos mateiras didáticos da EPPA se encontra em Língua Portuguesa. Em consequência disso, e pelo fato dos surdos não terem o domínio da L2, dos 51 surdos apenas um procurou a biblioteca para leituras. E, conforme a bibliotecária, os surdos, 
por serem muito visuais e também por não terem o domínio satisfatório da estrutura da Língua Portuguesa, leem, preferencialmente, gibis e livros escritos em quadrinhos, utilizando-se das imagens para complementar a compreensão e o sentido do texto.

Essa limitação na leitura em Língua Portuguesa, a nosso ver, traz algumas implicações no tocante à construção da competência em informação, já que a maioria dos materiais didáticos da Escola e os conteúdos de diversos sites de busca são disponibilizados exclusivamente em Língua Portuguesa, o que, a nosso ver, representa uma lacuna no desenvolvimento da competência em informação.

Contudo, o conjunto, formado pela práxis dos professores e alunos surdos da EPAA, a base legal, a realidade contextual, os conteúdos curriculares e os recursos pedagógicos utilizados vão, mesmo com algumas fragilidades, dando materialidade à Política Nacional de Educação Especial na Perspectiva da Educação Inclusiva e ganhando visibilidade na Escola, contribuindo, assim, para que os alunos surdos possam construir competência em informação.

\section{I Um olhar empirico sobre a ação de informação}

As ações de informação evidenciadas no espaço do Regime de Informação da Escola Professora Adelina Almeida (EPAA), através desta pesquisa-ação, tiveram como âncora os construtos teóricos de Freire (2013), que, baseada em González de Gómez (2003b), nortearam a nossa trilha para a identificação das três modalidades de ações aqui abordadas.

A primeira delas, ação de mediação que se apresenta através dos momentos de formação de professores, os quais são realizados semanalmente durante as aulas-atividades, através das palestras e projetos realizados em parceria com as universidades da Região, a exemplo da Universidade Federal do Vale do São Francisco (UNIVASF), da Universidade de Pernambuco (UPE - Campus Petrolina) e da Universidade Estadual da Bahia (UNEB - Campus Juazeiro).

Essa ação também se faz presente através de oficinas realizadas por professoras formadoras da própria escola, tanto em estudos mensais para tratar dos aspectos políticos e pedagógicos do Atendimento Educacional Especializado (AEE) como no estudo dos conteúdos de formação geral para o ensino, a partir do Pacto Nacional pelo Fortalecimento do Ensino Médio e , ainda, as ações de informação, realizadas pela educadora de apoio e pela professora de AEE, a exemplo da formação de professores (palestras, oficinas, atividades de ensino em si e, de forma mais ampla, aulas de Libras), sistematizadas num dispositivo de informação denominado Plano de AEE, que estabelece uma sintonia com as demandas da comunidade escolar, em especial, dos alunos surdos.

Já a modalidade de ação formativa, foi visualizada nas atividades de ensino em si, através das disciplinas do currículo, do ensino de Libras (que ocorre no contraturno mediado pelo professor instrutor) e do ensino em Libras (que ocorre na sala de aula regular, mediado por um intérprete de Libras e também na sala de Atendimento Educacional Especializado ou sala multifuncional) e, ainda, através da oferta, à comunidade interna e externa, de curso voltado para a proficiência em Libras, nos níveis básico, intermediário e avançado, com uma carga-horária total de 40 horas. Essa modalidade como parte integrante do estrato mimeomórfico da infraestrutura da informação, faz referência, também, as atividades de inovação e aos materiais de apoio, a exemplo da tecnologia assistiva.

Por sua vez, a relacional, que assume o caráter de meta-informação e a materialização na escola-campo-de-pesquisa, através de oficinas e de relatórios de pesquisa realizados por pesquisadores da Região do Vale do São Francisco, cujo trabalho tem propiciado intervenções de melhoria nas ações desenvolvidas na EPAA. Foi evidenciada, também, através do projeto A inclusão começa em mim. Um trabalho relevante que está sendo desenvolvido no AEE, com a parceria da Universidade Federal do Vale do São Francisco (UNIVASF) e visa discutir os limites e as possibilidades que têm os professores para o desenvolvimento do trabalho de inclusão.

Essa modalidade de ação, enquanto estrato inserido no domínio regulatório e definido nos espaços institucionais do Estado, do Campo Científico, da Educação Formal, da Legislação e dos Contratos, também se manifestam no Atendimento Educacional Especializado (AEE), 
através do exposto nas nas políticas educacionais e nas bases legais que o regulamentam.

Todavia no escopo da Escola Professora Adelina Almeida (EPAA), e considerando o Atendimento Educacional Especializado (AEE) para pessoas com deficiência auditiva, o conjunto dessas ações de informação, aqui tratadas como "estratos heterogêneos articulados", se manifesta em aulas expositivas e dialogadas, nos momentos de formação de professores, nas palestras envolvendo a comunidade escolar, oficinas, seminários e projetos diversos. (GONZÁLEZ DE GÓMEZ, 2003b). Com efeito, esse modelo teórico de ações de informação, apresentado por González de Gómez, (2003b), encontra-se materializado no cotidiano da Escola Professora Adelina Almeida (EPAA), através de seus atores - aqui representados pela comunidade da EPAA (pais, alunos, professores, gestores, coordenadores, analistas, instrutores e interpretes de Libras).

Nesse sentido, inspirados em Freire (2014), apresentamos, através da figura 1, os estratos e as especificações das ações de informação desenvolvidas pelos atores sociais da Escola professora Adelina Almeida (EPAA). A nosso ver, esse desenho evidencia o resultado da nossa pesquisa, identificado a partir de fontes de informações diversas, caminhando pela trilha metodológica traçada para o seu desenvolvimento, cujos resultados vão se conformando para o desvelamento da construção de competência em informação pelos atores envolvidos.

Figura 1 - Ações de Informação na EPAA

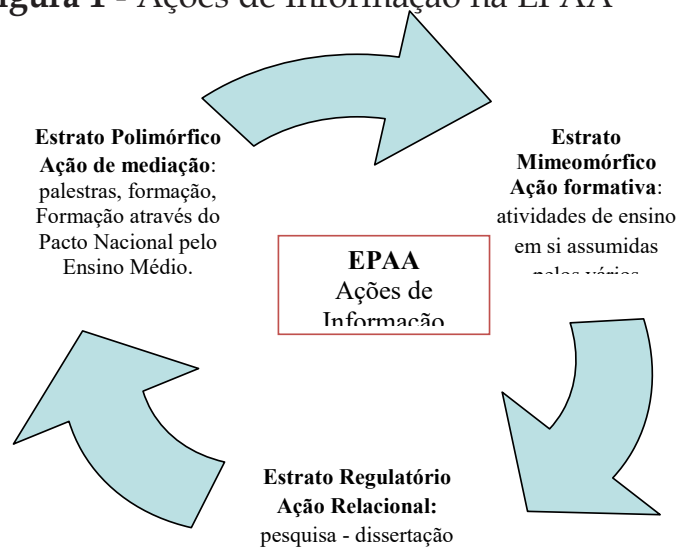

Fonte: Adaptado de Freire (2014) baseado em Gonzalez de Gómez (2003).
Convém ressaltar que, à medida que os atores sociais participam e atuam nas ações de informação (relacional, mediação ou formativa) no Regime de Informação da EPAA, percebemse algumas lacunas na comunicação, em especial na comunicação entre os professores de AEE e os professores dos vários componentes curriculares da Escola. Esse descompasso na comunicação, na visão dos docentes do AEE, tem se dado em função da concepção que muitos professores do ensino regular têm do AEE e do seu entendimento acerca das formas pelas quais o aluno surdo aprende e constrói sua competência em informação, uma concepção que, em alguns aspectos, difere do entendimento dos professores do AEE. Isso, na visão dos professores de $\mathrm{AEE}$, interfere no atendimento educacional especializado e no direcionamento e aplicabilidade da Política Nacional de Educação Especial numa Perspectiva da Educação Inclusiva, constituindo num obstáculo à construção de competência em informação como mostra a figura 2.

Figura 2 - Barreiras no desenvolvimento de competência em informação

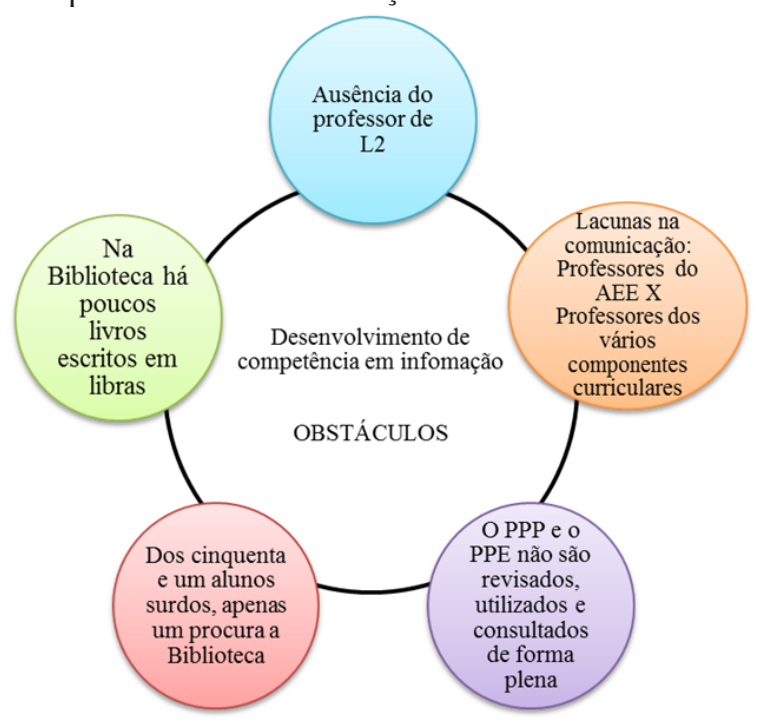

Fonte: Elaboração da autora (2016).

Contudo, mesmo com algumas fragilidades, podemos observar que as ações de informação desenvolvidas nas organizações, a partir dos estratos articulados se traduzem em envergadura informacional que, compartilhada 
por todos os atores sociais, passam a se configurar em uma forma de vida desses atores, para além da formação de um espaço de construção do conhecimento, da cultura e da busca permanente de subsídios para o desenvolvimento de competência em informação, na perspectiva da inclusão social.

\section{CONSIDERAÇOES FINAIS}

Essa pesquisa-ação teve como propósito investigar o espaço que ocupa o Atendimento Educacional Especializado (AEE) na Escola Professora Adelina Almeida em PetrolinaPE, na perspectiva do desenvolvimento de competências em informação para inclusão social de alunos surdos. Um caminho trilhado a partir de um quadro teórico-metodológico que nos confiou reflexões pertinentes à construção do nosso entendimento sobre a competência em informação e a identificação dos elementos a ela relacionados.

A identificação desses elementos certamente não seria visível para nós sem as contribuições teóricas dos gigantes aqui citados, em cujos ombros nos apoiamos. Foi, ainda, a partir desses modelos teóricos-metodológicos que constatamos a importância de cruzar vários olhares na busca do entendimento do que seja competência em informação, para escolher quais caminhos trilhar para encontrar evidências que comprovem o desenvolvimento das competências em informação para os sujeitos envolvidos da EPAA, em especial, aos professores de AEE e alunos surdos.

Todavia, do ponto de vista do nosso trabalho de pesquisa, foi um encontro teóricoprático, que suscitou a identificação das ações de informação desenvolvidas pelos atores sociais que fazem parte da escola campo de pesquisa, permitindo algumas reflexões conclusivas que, para nós, se constituem em resultados da caça às evidências dos elementos da competência informacional para inclusão social de alunos surdos, na escola-campo-dapesquisa.

Entre essas reflexões, destacamos a relevância dada à informação na escola, a partir da identificação de ações concretas voltadas para o desenvolvimento de competências em informações a exemplo das formações continuadas, cursos de proficiência em Libras, criação dos espaços de debate para discutir formas de melhor administrar a inclusão social dos alunos, e ações de ensino em si. Essas ações de informação, desenvolvidas pelos atores sociais da EPAA, constituem possibilidades de promoção e desenvolvimento das "competências necessárias para a socialização da informação" e para a construção de competências em informação (FREIRE, 2012, p.11).

Torna-se pertinente ressaltar que as tecnologias digitais de informação e comunicação também encontram espaço no Regime de Informação da EPAA. Assim, durante a nossa pesquisa, evidenciamos que, em razão da deficiência auditiva dos alunos matriculados na escola campo de pesquisa, um recurso tecnológico, bastante utilizado pelos professores e alunos para o estabelecimento de uma comunicação rápida e efetiva, tem sido as mensagens de texto, enviadas através de celular e e-mail, sendo a forma de comunicação dominante, utilizada, inclusive, pelos surdos na comunicação entre seus pares.

De modo que, tendo em vista o nosso interesse prático e a nossa "finalidade intencional de alteração da situação pesquisada" (SEVERINO, 2007, p. 120), as observações e análises dos dados coletados possibilitaram a identificação de elementos de competência em informacional e também de algumas lacunas. Todavia, foram essas lacunas que potencializam, na comunidade escolar, a construção de novos esforços, novas leituras e ações na direção da competência informacional.

Essa observância fortalece o entendimento de que as ações de informação desenvolvidas na EPAA, realizadas através do AEE, passem a se configurar numa forma de vida desses atores para além da formação de um espaço profissional, na direção da construção do conhecimento, da cultura surda e da busca permanente de subsídios para o desenvolvimento de competências em informação para a inclusão social.

Sem deixar de reconhecer que que esta pesquisa não se encerra em si mesma e que, por conseguinte, ao revelar seu aspecto inconcluso suscita novos olhares desveladores da realidade dinâmica da hegemonia do regime de informação, na sociedade contemporânea. 
Artigo recebido em 8/0I/2016 e aceito para publicação em I8/02/2017

\title{
A LOOK OVER SCHOOL EDUCATION OF DEAF IN THE LIGHT OF INFORMATION LITERACY
}

\begin{abstract}
This article is about the school education of the deaf in the light of information literacy, taking as reference the Customer Specialized Education (AEE) for deaf people. It presents the theoretical framework approach the legal and pedagogical aspects of the ESA, here treated as locus of Educational Service Specialist. Approaches, theoretical aspects of information literacy and information actions. It aims to analyze the ESA School Professor Adelina Almeida in Petrolina PE, from the perspective of competence development in information for social inclusion of deaf students. The investigation of the object of study has the north to action research, applied nature, a qualitative approach, the results show concrete actions for the development of competence in information and potentiating new teaching strategies in driving learning always and in all dimensions of life.
\end{abstract}

Keywords: $\quad$ Educational Service Specialist. Deaf inclusion. Information competence. Share information. Bilingual approach.

\section{REFERÊNCIAS}

AMADEO, D. dos S. Necessidades Informacionais dos alunos do curso de letras libras quanto à realização de pesquisas acadêmicas: um olhar inicial ao desenvolvimento da Competência Informacional dos alunos surdos. Florianópolis: 2012. Disponível em: <http://portal.febab.org. br/anais/article/viewFile/1417/1418>. Acesso em: jan. 2015.

ARAUJO, H. de. História de luta das pessoas com deficiência em Petrolina. Petrolina: Franciscana, 2015.

BRASIL, Decreto $\mathrm{n}^{0} 5.626$, de 22 de julho de 2005. Regulamentação da Lei $\mathrm{n}^{\circ} 10.436$, de 24 de abril de 2002, dispõe sobre a Língua Brasileira de Sinais - Libras, Brasília: MEC. 2005.

Manual de Orientação: Programa de Implantação de Sala de Recursos Multifuncionais. Brasília: MEC/Secretaria Executiva/ Secretaria de Educação Especial/SEESP, 2010.
BRASILEIRO, A. M. M. Manual de Produção de Textos Acadêmicos Científicos. São Paulo: Editora Atlas AS, 2013.

CASTELLS, M.A galáxia da Internet: reflexões sobre a internet, os negócios e a sociedade. Rio de Janeiro: Zahar, 2003.

DAMÁZIO, M. F M. Atendimento Educacional Especializado para Pessoas com Surdez. Curitiba: Cromos, 2007.

FREIRE, I. Sobre o Regime de Informação no Laboratório de Tecnologias Intelectuais - LTi. CID. R. Ci. Inf. e Doc. Ribeirão Preto, v. 4, n. 1, p. 70-86, jan./jun. 2013. Disponível em: <http://www.revistas.usp.br/incid/article/ view/59102>. Acesso em: jun. 2015.

Tecendo uma rede conceitual na ciência da informação: tecnologias intelectuais para competências em informação. Informação;Tecnologia (ITEC),Marília/João Pessoa, v. 1, n.1, pp. 130-144, 2014. Disponível em: <http://periodicos.ufpb.br/ojs/index.php/ 
itec/article/download/19840/11017>. Acesso em: jun. 2014.

FREIRE, G. H. A ; FREIRE, I. Ações para competências em informação no ciberespaço: Reflexões sobre a Contribuição da Metacognição. Encontros: revista eletrônica de biblioteconomia e ciência da informação.V. 17, n. esp.1, pp.1-23, 2012. Disponível em:<https://periódicos.ufsc. br/índex.php/eb/article/view//1518- 924.2012. v17nesp1p1>. Acesso em: mar. 2015.

GONZALEZ DE GOMEZ, M. N.As relações entre ciência, Estado e sociedade: um domínio de visibilidade para as questões da informação. Ciência da Informação. Brasília, v. 32, n. 1, pp. 60-76, 2003a.

Escopo e abrangência da ciência da informação e a pós - graduação na área: anotações para uma reflexão. Transformação. Campinas, v. 15., n 1, pp. 31-43, 2003 b.

JONNAERT, P. Currículo e Competências. Porto Alegre: Artmed,2010.

LÉVY, P. As tecnologias da inteligência. Rio de Janeiro: Ed. 34, 1993.

MORAN, J. M. Ensino e aprendizagem inovadores com apoio das tecnologias. MASETTO, M. T.; MORAN, J. M ; BEHRENS, M. A. Novas tecnologias e mediação pedagógica. Campinas: Papirus, 2013.
NASCIMENTO, S. G. V. do, FREIRE, G. H. de A. ; DIAS, G. A. A tecnologia da informação e a gestão pública. MPGOA, João Pessoa, v.1, n.1, pp. 167-182, 2012.

PERRENOUD. F. Dez Novas Competências para ensinar. Porto Alegre: Artes Médicas Sul, 2000.

\section{Desenvolver competências ou ensinar}

saberes? AEscola que prepara para a vida. Porto Alegre: Penso, 2013.

ROPÉ, F. ; TANGUY, L. Saberes e competências: O uso de tais noções na escola. Campinas SP: Papirus, 1997.

SACRISTÁN, J. G.A Educação que ainda é possível: ensaio sobre uma cultura para a educação. Porto Alegre: Artmed, 2007.

SEVERINO, A. J. Metodologia do Trabalho Científico. São Paulo: Cortez, 2007.

SILVA NETO. C. E da ; FREIRE.G.H. de A.Competência em Informação: relato de experiência. Racin, João pessoa, v. 2, n. 2, pp. 44-63, 2014.Disponível em: <racin.arquivologiauepb. com.br/edicoes/v2_n2/racin_v2_n2_artigo03.pdf>. Acesso em: mai. 2015.

STROOBANTS, M. A visibilidade das competências. In: ROPÉ, F. ; TANGUY, L. (orgs). Saberes e competências: $\mathrm{O}$ uso de tais noções na escola. Campinas: Papirus, 1997. 